\title{
Simulation of the operation of hydro plants in an electricity market using Agent-Based Models
}

\author{
José Carlos Sousa \\ FEUP/DEEC and EDP Produção \\ Rua Dr. Roberto Frias, \\ 4200-465 Porto, Portugal \\ jose.sousa@edp.pt
}

\begin{abstract}
The optimization and simulation of power systems continues to be an area of concern for electricity companies and researchers worldwide namely considering the development of electricity markets and competition in the generation activity Therefore generation companies are devoting an increasing attention to market issues justifying the development of models to help them preparing bidding strategies to the day-ahead market. In this context, agent-based models have been reported as a complement to optimization and equilibrium models when the problem is too complex to be analyzed by traditional approaches. This paper details an Agent-Based Model for an electricity market considering a detailed modeling for hydro stations and presents some preliminary results taking the Iberian Electricity Market as an example.
\end{abstract}

Index Terms--hydro stations, electricity markets, operation planning, agent-based models.

\section{INTRODUCTION}

In the scope of the development of electricity markets, the optimization of the operation of the hydro power plants has been regaining interest both among the research community and the electricity industry. This is certainly due to the change of paradigm determining the operation of power systems given the increased competition between market agents and the increase renewable energy share in power systems. In fact, hydro power plants have always been known for their large reliability and availability and also given their reduced response times. Currently, the existence of storage capabilities in an increasing number of hydro plants turns the management of these assets very important to the generation companies as a well to increase the overall revenues. On the other hand, the mentioned reduced response times turn hydro stations also very appealing as a very efficient way to provide reserve services so that they are becoming more and more important from the point of view of the TSO's. Finally, their reduced response times combined with storage capability turn hydro stations as an important technology to help the management of power systems having a large share of renewable generation associated to volatile primary resources as wind and solar.

Taking into account these concerns, it becomes important to develop new models so that generation companies can

\author{
João Tomé Saraiva \\ FEUP/DEEC and INESC TEC \\ Rua Dr. Roberto Frias, \\ 4200-465 Porto, Portugal \\ jsaraiva@fe.up.pt
}

adequately plan the operation of hydro stations under competition. The role of modeling and simulation models to support decision-making in complex systems, as for example electricity markets, has been widely established as a valid technique. Recently, agent-based models were reported as a complement to equilibrium models when the problem is too complex to be analyzed by traditional models. Agent-based simulation follows the metaphor of autonomous agents and multi-agent systems as the basis to conceptualize complex systems. That is, a model is built taking advantage of the interaction between agents acting in a simulation environment.

There are several approaches in the literature to the simulation of generation systems in market environment. However, the presence of a large share of hydro generation, specially pumping hydro, is not adequately treated [1]. Accordingly, this paper models the problem on an agent-based environment and presents results for the operation of an electricity market considering hydro stations and taking the Iberian Electricity Market, MIBEL as the illustrative example. We considered four types of hydro plants: run of river stations, storage stations, pumping storage stations and pure pumping stations. Hydro plants are modeled as agents that can produce and also consume (in the pumping case) meaning that they have to negotiate energy in the market as introduced in [2]. To support the hydro-pumping decisions different optimization models were already developed [3,4] namely using nonlinear programming and Genetic Algorithms.

Taking these ideas into account, this paper is structured as follows. After this introduction, Section II overviews the Iberian Electricity Market, given that the simulation of this market is the one of the goals of this research. Then, Section III gives an overview on existing approaches to deal with the hydro scheduling with particular emphasis on agent-based models. Section IV describes the proposed agent-based model and Section V details the results obtained so far. Finally Section VI draws the most relevant conclusions.

\section{ELECTRICITY MARKETS REVIEW}

\section{A. New Structures and the Unbundling Model}

To allow an appropriate development of electricity markets, significant changes were needed in power systems. In 
this context, electricity shall be regarded as a product traded in a competitive environment within certain rules. In this new framework, companies are seen as service providers and the grids correspond to the physical locations where electricity markets are established. On the other hand, in order to ensure that the whole system operates properly, independent entities, (both at a technical and at a regulatory level) are required.

The electricity sector restructuring originated the unbundling of the traditional vertically integrated companies and the creation of a disaggregated structure involving activities covering the entire value chain, namely generation, transmission, distribution and retailing. It also includes multiple actors as regulatory agencies, market and system operators, and several agents in the generation and retailing activities that are provided under competition.

In general, generation and retailing are provided under competition while transmission and distribution grid activities are organized in regulated monopolies. In order to balance the demand and the supply new mechanisms have emerged, namely the day-ahead pool markets. The day-ahead markets that exist in several European countries correspond to short term forward markets based on the matching of the selling and buying bids for each hour of the next day. The market clearing prices are typically obtained under a marginal basis and are usually volatile, especially in countries where hydro and other renewable energies are present in large scale (as in MIBEL). In order to be aware of this volatility, longer term contracts are also possible under different horizons and conditions.

\section{B. The Iberian Electricity Market, MIBEL}

Portugal and Spain power systems went through several changes in last decades. In Portugal, the power industry was nationalized in the 1970 s with the creation of a vertically integrated utility. This organization started to change in 1995 when a new electricity law was passed admitting the coexistence of a public and a market driven sector. Later, in 2006 a new electricity law was passed organizing the industry in generation, transmission, distribution and retailing. The Regulatory Agency was created in 1995 and is responsible for the publication of several codes and for setting the regulated tariffs. Since 2007, all clients are eligible and the free market represented $73 \%$ of the demand by the end of 2013 .

In Spain the power system was also organized in terms of vertically integrated utilities having a regional distribution. Then a new law was also passed in 1995 in a first attempt to introduce some competitive mechanism in the system. Later on, by the end of 1997 a new law was approved so that the Spanish electricity day-ahead market was in place in the 1st of January 1998. Since then, a fast transition of regulated captive clients to the free market was implemented so that full eligibility was achieved in 2003.

The implementation of MIBEL started with the signature of a memorandum by the Portuguese and Spanish governments in 2001. After several delays, a common bilateral contract trading mechanism was set in place in 2006 and the joint day-ahead market started in the 1st of July 2007 as an extension of the already existing Spanish day-ahead market. In the first operation years the electricity prices in the two areas were different in a large number of hours due to the application of market splitting to solve congestion in the interconnections. Nowadays, due to the increase of the interconnection capacity and the increasing share of generation in distribution networks, transmission grids are less loaded so that the number of congested hours declined. As a result the prices in the two countries converged to common values in almost $85 \%$ of the hours in 2013 and 2014 .

Regarding the generation mix, both countries have a large share of hydro plants with a huge variation in their annual output. In terms of the renewable share, both countries were very successful in increasing the amount of renewables. This corresponded to a strategic policy adopted by successive governments to use more intensively endogenous resources, to enlarge the energetic independency and also to develop new industrial activities thus creating new jobs. By the end of 2014 , wind power reached an installed capacity of $5270 \mathrm{MW}$ out of 17827 MW in Portugal (30\%) and of 22854 MW out of 102259 MW in Spain (22\%) with a contribution to supply the demand of $25 \%$ in Portugal and $21 \%$ in Spain.

\section{LITERATURE REVIEW ON HYDRO SCHEDULING}

\section{A. Hydro Scheduling Optimization}

Generation companies having hydro power plants in their portfolio have to identify the most adequate operation strategy in order to maximize their profit. In a competitive environment, they have to build selling bids (and buying when they have pumping) and send them to the day-ahead market operator. In addition to the uncertainty associated to the hydro conditions, the optimization of hydro power plants is a complex and nonlinear problem namely due to the nonlinear relation between the power, the flow and net head. The literature includes a large number of publications on this topic. In this scope, [5] uses dynamic programming but this technique usually leads to the well-known "curse of dimensionality". Other publications use mixed integer linear programming [6] or meta-heuristics, as Simulated Annealing [7], Neural Networks [8] or Genetic Algorithms [4]. The mentioned nonlinear relation can also be addressed using an iterative procedure as described in [3].

\section{B. Electricity Markets Modeling}

There are several works that were developed to model electricity markets using different techniques that can be organized in four main areas [9]:

- Optimization problems, addressing a single company also known as single firm optimization models;

- Equilibrium Models based on Game Theory, considering a larger number of competitors;

- Agent-Based Models, ABM, that simulate the behavior of the companies and the interactions between agents;

- Hybrid solutions.

Optimization models typically address the maximization of the revenues of a single company, often considered as a price taker. Some examples were described in section III-A. Equilibrium Models represent the market behavior considering the competition between all participants. More recently, Agent-Based Models became an interesting 
alternative when the complex level prevents using traditional equilibrium framework. Agent-based computational economics (ACE) corresponds to the computational study of economic dynamic systems modelled as virtual worlds of interacting autonomous agents in an environment.

\section{Agent-Based Models in Electricity Markets}

There are several models in the literature addressing this issue as AMES (Agent-based Modeling of Electricity Systems), EMCAS (Electricity Market Complex Adaptive Systems) and MASCEM (Multi Agent based Electricity Market). AMES is an open source platform that allows the simulation of strategic trading behaviors in restructured markets considering AC grids [10]. EMCAS is a commercial ABM software developed by the Argone National Lab having the capability of taking decentralized decision-making along with learning and adaptation for agents. An EMCAS simulation includes both the end users and the demand companies from whom they purchase electricity. EMCAS is linked to VALORAGUA model [11] that provides longer term operation planning strategies for hydro plants. With this information, EMCAS uses the price forecasts and weekly hydro schedules given by VALORAGUA to provide intraweek hydro plant optimization for hourly supply offers. Finally, the MASCEM is a simulation platform based on a multi-agent framework [12]. It includes agents with strategies for bid definition, acting in forward, day-ahead, and balancing markets and considering both simple and complex bids turning it both in a short and a medium term model.

Nevertheless, hydro generation, specially pumping hydro stations, is not adequately characterized taking into account the increase of renewable volatile sources. For instance, EMCAS includes the VALORAGUA model turning it very dependent on the performance of the VALORAGUA. This also means that EMCAS does not include the definition of bidding strategies to hydro power plants. Taking this into account, the main objective of this research is to simulate hydro generation in a market environment using an ABM platform, especially regarding hydro with pumping given the extra flexibility these stations have in terms of buying electricity in off peak hours when eventually extra wind generation is available and selling it in peak hours. This will allow us to study their impact on systems having a large penetration of renewable sources, especially wind.

\section{DeVeloped Agent-Based Model}

As mentioned before the main goal of this paper is to present a model for hydro plants agents in an Agent-Based framework, based on the model introduced in [1] and in [2].

\section{A. Hydro Agents}

Hydro station agents bid their energy in the market and their strategy is very dependent on the type of reservoir and inflows. Depending on the hydro type, the bidding price strategy is determined by the water value on the reservoir, by a learning parameter $\alpha$ and by a decision supporting tool, all of them originally described in [2] and modeled as (1). In a first approach, this bid price has the same value for every hour of the next day, except for pure pumping plants. The water value function $f$ (water value) provides each plant with a reference bid price that changes every day depending on the reservoir level, as illustrated in Figure 1. This means that if the level is larger, then the value of the water stored is more reduced and so a more reduced biding price can also be used. This water value function is calculated for each weak according to the procedure detailed in [2].

$$
\text { Bid price strategy }=f(\text { water value })+\text { bid up/down }(\alpha)
$$

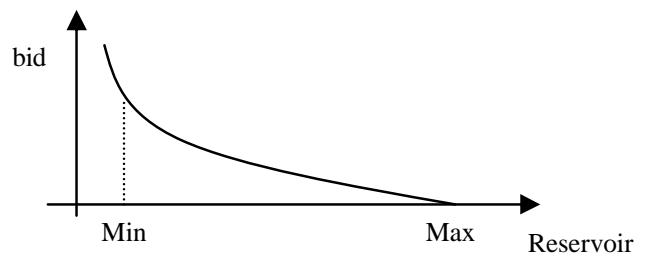

Figure 1. Base bidding taking into account the water value.

The bid up/down $(\alpha)$ parameter models the strategy of each agent by increasing or decreasing its bid price as a way to increase the profit. This parameter is given by a learning procedure modeled using a sigmoid function that reflects the risk profile of each agent. If an agent has a higher risk profile, the bid range will be larger. On the other hand, a low risk profile will lead to a lower bid range as illustrated in Figure 2 for hydro agents having different risk profiles. This strategy is an adaptation of the derivative-following strategy discussed in [13] and also used in [12]. A derivative follower does incremental increases (or decreases) in price, continuing to move its price in the same direction until the observed profitability level falls. At this point, the direction of the movement is reversed. In future works, this strategy will be combined will a Q-learning procedure.
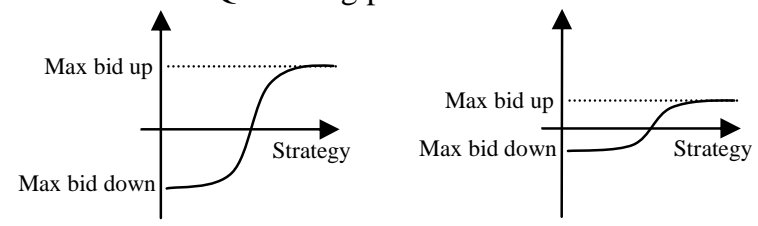

Figure 2. Bidding strategy taking into account the risk profile of each agent.

The developed ABM model 4 considers four types of hydro agents having different bidding strategies:

- Run of river - these agents typically have a water value function near 0 , so they will have more focus on their bid up/down strategy;

- Storage - these agents will have a bid value directed related to their water value function as well as to their bid up/down strategy;

- Storage with pumping - the bid price is linked to their water value function and a bid up/down strategy. They also have the possibility of buying energy to pump water to their reservoir, taking advantage of low prices;

- Pure pumping - these agents are assigned a zero water value because these reservoirs are usually small. They will use decision support tools to forecast the dayahead electricity prices so that they can define an arbitrage strategy based on price differential between peak and off peak hours. Given that forecasted and real market prices can differ, the energy used in pumping is limited by a parameter $\beta$. This parameter is updated 
along the simulation and it reflects the relation between the forecasted prices and the real market prices. When an agent decides to pump, it has an expectation for the next day market prices. But in real time there is a risk that on generation periods the real price is below the expected one and on pumping periods the real price is above the expected one turning pumping less profitable. Therefore, this parameter is updated to address this risk using a learning procedure.

\section{B. Thermal and Renewable Generation Agents}

These agents have a strategy similar to the hydro agents, but the water value function is substituted by their marginal cost. Renewable agents bid at $0 € / \mathrm{MWh}$ in order to model their dispatch priority according to the Portuguese legislation.

\section{Market and System Operator Agents}

The Market Operator agent is an artifact agent, given that it has not an associated decision making process [1]. It performs the market clearing operations determining the market price and communicating the market results to all market agents. Regarding the System Operator, in this phase this agent is not used. In future developments, it will manage the ancillary service markets, namely to determine the amount of secondary and tertiary reserve to procure and contract.

\section{Inelastica and Elastic Consumer Agents}

These include two types of agents: inelastic agents that buy energy at the maximum value allowed in the MIBEL rules (180 €/MWh), and elastic agents that are designed to model the behaviour of consumers that can directly participate in the market, typically large industries or hydro pumping stations. Elastic consumers will be responsible for some demand response regarding price variations in their buying curves.

\section{E. Regulater Agent}

This agent monitors the generator bids and can penalize these agents if the bid prices are very different of the marginal cost regarding thermal stations or of the water value for hydro stations. It also has the possibility of imposing a limit to the bidding prices so that they adhere more closely to the marginal cost of thermal stations or to the water value of hydro stations.

\section{PRELIMINARy Results}

The test case was based on a simplified version of the Portuguese generation system, to allow a better analysis of the results. We considered 22 hydro power plants having constant inflows and 11 thermal (coal and natural gas) units. The generation mix also includes 5 reservoir pumping plants. In a first step, wind and PV units were set constant for all hours at 2000 MW. Then we used the 2013 historical generation profile for these units. The demand is assumed totally inelastic and prepared to pay the maximum price admitted in MIBEL, $180 € / \mathrm{MWh}$. Initially, the demand has a daily constant profile and then we used the 2013 demand data.

\section{A. Generation companies without strategies}

The first simulation assumes that generation companies bid without any special strategy, that is, their bids simply reflect the operation marginal cost of each station. On the other hand constant profiles were used for the demand and for the wind and PV units. Figure 3 shows the market price results if the generators bid their variable cost. The off peak prices are determined by run of river hydro and coal plants, while the peak prices result from bids from natural gas and reservoir plans. In this simulation we did not consider the possibility of pumping neither the monitoring action of the regulator.

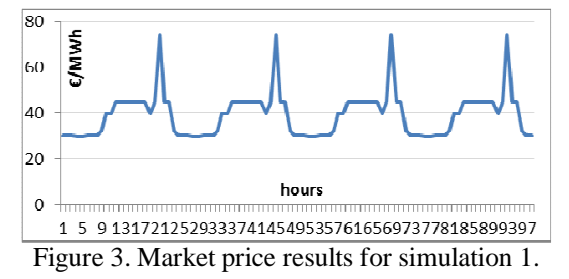

\section{B. Generation companies with strategies}

In the second simulation we considered that all generators have an higher risk profile which means that they will do aggressive bids up and down (for example all increasing or decreasing the bids by $1 € / \mathrm{MWh}$ in each iteration). Figure 4 shows the market price results. Although there is no communication between generators, after same time all of them start biding close to $180 € / \mathrm{MWh}$, which is the maximum price the demand is prepared to pay. Given that the demand is completely inelastic, they rapidly realize that if they all bid the maximum price they will maximize their profits.

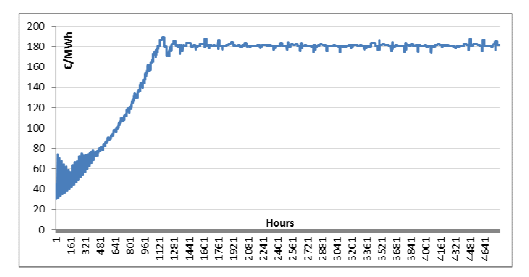

Figure 4. Market prices results for simulation 1.

However, in real markets this doesn't happen because not all generators behave in the same way and there is a regulator to monitor and eventually penalize them. Figure 5 presents the results admitting that the Regulator Agent limits the bids by $20 \%$ of the generators marginal cost, as well as the results considering that generators have different risk profiles so that they can change they bid price along the simulation. If the bid prices is limited (blue line), the market prices are more stable. However, we are introducing an artificial limit in the simulation that has an impact in competition. The red line represents the results considering that the regulator doesn't limit the bid prices but generators have different bid strategies, that is different risk profiles. The results show that competition is now working and prices are very similar to the ones obtained considering the regulator limitation. In this case, a consecutive bid up made by a risky generator trying to maximize the profit may not be successful because the other generators have different risk profiles and do not follow the same strategy. For this reason, in our work we will consider that generators have different risk profiles and the regulator will not limit the bids, but instead it will check if the bids are excessively higher regarding the marginal cost. If that happens, the profit of the associated agents is penalized. 


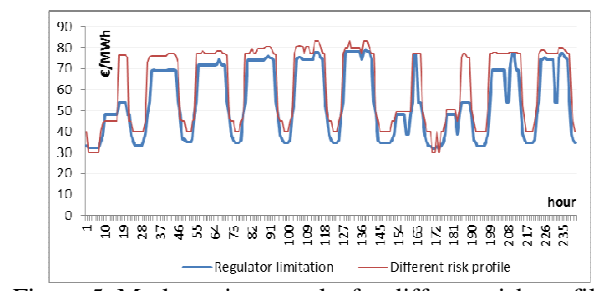

Figure 5. Market prices results for different risk profiles.

\section{Using the 2013 renewable and demand profiles}

The use of the real wind, PV and demand profiles for 2013 turns this simulation closer to reality. Initially we ran a simulation using these profiles, and then the number of natural gas plants was increased to foster competition. Figure 6 presents the results obtained for these two simulations.

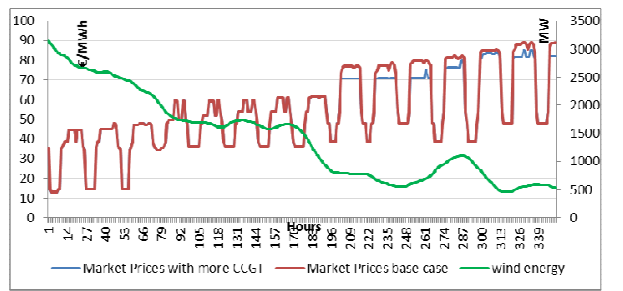

Figure 6. Market prices results for 2013 wind and demand profile.

As expected the markets prices are higher when wind energy is more reduced. In fact on the right side of Figure 6, wind energy is more reduced and market prices are close to 90 $€ / M W h$ when the higher marginal operation cost is 75 $€ / M W h$. In blue we can also observe the impact of having more competition on peak periods due to more natural gas power plants and leading to peak price reductions. Table 1 has the annual average market prices for these simulations.

Table 1. Average market prices using the 2013 profiles.

\begin{tabular}{|l|c|}
\hline \multicolumn{1}{|c|}{$\begin{array}{c}\text { Simulation with 2013 wind, PV } \\
\text { and demand profiles }\end{array}$} & $\begin{array}{c}\text { Average annual Market } \\
\text { Price ( } \mathbf{f} / \mathbf{M W h})\end{array}$ \\
\hline Bid at the marginal operation cost & 41.22 \\
\hline All Generators with higher risk & 171.08 \\
\hline Generators with different risk profiles & 47.02 \\
\hline More natural gas units & 45.13 \\
\hline
\end{tabular}

\section{Comparison results without pumping hydros}

Finally, we analyzed a period having a large amount of wind energy with and without pumping stations. The results in Figure 7 show that if pumping is included, then zero price periods are more reduced suggesting that pumping hydro plants are able to do price arbitrage and to behave as price makers. This means they have to consider the difference between forecasted and real prices as a way to minimize their risk. In this case, this risk was modeled as detailed in [5].

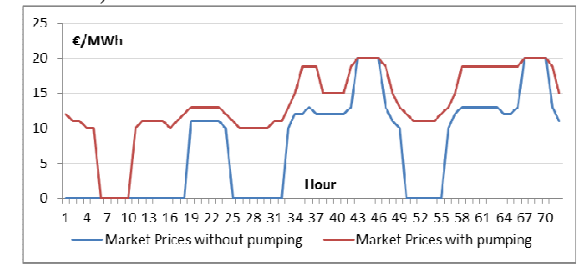

Figure 7. Impact in market prices of having pumping hydro.

\section{CONCLUSIONS}

This paper presents the preliminary results of an ABM model to simulate the electricity market focusing on modeling hydro units. The obtained results confirm the agents have learning capabilities and are maximizing their profit. We also observe the importance of regulation in this kind of markets and that competition is able to decrease the market prices namely when considering more CCGT's. On the other hand, having an accurate model for hydro pumping units is very important in the Portuguese case because these units often behave as price makers. In future works, this model will be extended to include the Spanish generation system and a Qlearning process to improve the learning capabilities of the generation agents. Finally, the model will be completed including ancillary services markets namely for reserves.

\section{ACKNOWLEDGMENT}

The authors thank for the contributions of Z. Kokkinogenis, R. Rossetti and A. P. Rocha from LIAC - Artificial Intelligence and Computers Sciences Laboratory (FEUP).

\section{REFERENCES}

[1] J. C. Sousa, Z. Kokkinogenis, R. Rossetti, J. T. Saraiva, "Electricity Market Modeling and Renewable Energy Integration: an Agent-Based Conceptual Model", in Proc.10th Int. Multidisciplinary Modeling \& Simulation Multiconference, I3M/SESDE 2013, Athens, Sept. 2013.

[2] J. C. Sousa, J. T. Saraiva, Z. Kokkinogenis, R. Rossetti, "Operation Planning of Hydro Power Plants Using Agent Based Models", in Proc. of MedPower 2014, Athens, Nov. 2014

[3] J. C. Sousa, V. T. Mendes, J. T. Saraiva, "Estimation of the Remuneration of Hydro Plants in a Market Environment Using an Iterative Under-Relaxation Approach", in Proc. 2009 IEEE Bucharest Power Tech, Romenia, 28 June - 2 July 2009.

[4] Guerreiro, C.A., J. T. Saraiva, J. C. Sousa, V. T. Mendes, "Operation planning of hydro stations using genetic algorithms considering their impact on the electricity market prices", in Proc. $11^{\text {th }}$ International European Electricity Market Conference, EEM'14, Kracow, May 2014.

[5] S.-C. Chang, C.-H. Chen, I.-K. Fong, P. B. Luh, "Hydroelectric Generation Scheduling With An Effective Differential Dynamic Programming Algorithm”, IEEE Transactions on Power Systems, vol. 5, no. 3, pp. 737-743, August 1990.

[6] G. W. Wang, C. T. Su, "A Practical Mixed Integer Linear Programming Based Short Term Hydro Scheduling", in Proc. of the IEEE Asia-Pacific Trans. and Dist. Conference, vol. 3, pp. 1606-1610, October 2002.

[7] K. Wong, Y. Wong, "A Parallel Simulated Annealing Algorithm for Short-Term Hydro Scheduling", in Proc. of the IEEE Int Forum on Applications of Neural Networks Power Systems, pp. 335-340, April 1993.

[8] R. H. Liang, Y. Y. Hsu, "Short-Term Hydro-Scheduling using Hopfield Neural Network", IEE Proc. Generation, Transmission \& Distribution, vol. 143, no. 3, pp. 269-275, May 1996.

[9] G. Li, J. Shi, X. Qu, "Modeling methods for GenCo bidding strategy optimization in the liberalized electricity spot market-A state-of-the-art review", Energy, vol. 36, no. 8, pp. 4686-4700, August 2011.

[10]H. Li, L. Tesfatsion, "Development of open source software for power market research: The AMES test bed", Journal of Energy Markets, vol. 2, no. 2, pp. 111-128, 2009.

[11]P. Thimmapuram, T. D. Veselka, V. Koritarov, S. Vilela, R. Pereira, R. F. Silva, "Modeling hydro power plants in deregulated electricity markets: Integration and application of EMCAS and VALORAGUA", in Proc. EEM2008, pp. 1-6, May 2008.

[12]Z. Vale, T. Pinto, I. Praça, H. Morais, "MASCEM: electricity markets simulation with strategic agents", IEEE Transactions on Intelligent Systems, vol. 26, no. 2, pp. 9-17, March-April 2011.

[13]A. Greenwald, J. Kephart, and G. Tesauro, "Strategic Pricebots Dynamics," in Proceedings of the $1^{\text {st }}$ ACM Conf. Electronic Commerce, ACM Press, pp. 58-67, 1999. 